\title{
Thrombolysis after acute myocardial infarction
}

\author{
Patrick A Nee
}

The early treatment of acute myocardial infarction has become characterised by aggressive regimens aimed at limiting infarct size, the rapid treatment of arrhythmias and left ventricular dysfunction, and early evaluation for surgery or angioplasty. Intravenous thrombolytic (fibrinolytic) agents have become the mainstay of treatment for definite infarction and significant mortality and morbidity gains have been demonstrated with these drugs in a number of major studies.

\section{Background}

Thrombolysis began in 1933 when Tillet and Garner first isolated a fibrinolytic substance, which they called streptococcal fibrinolysin, from $\beta$ haemolytic streptococci. ${ }^{1}$ Christensen and Macleod renamed this substance streptokinase in 1945 and described its mechanism of action as converting plasminogen to plasmin which lyses fibrinogen and fibrin in coagulum. ${ }^{2}$ It was initially used clinically to debride infected tissue spaces such as chronic empyema and haemothorax. ${ }^{3}$ The purified streptokinase produced by Christensen after 1947 became used in early experiments which showed that prolonged intravenous infusion could dissolve intracoronary thrombus and limit infarct size. ${ }^{4}$

Little progress was made for the next two decades because of fears over systemic side effects, especially bleeding and allergy, and because attention was focused on the establishment of coronary care units (CCU) within most major hospitals - an initiative which itself led to significant mortality gains.

The current era began in 1980 when DeWood reported the use of coronary angiography to demonstrate thrombus within the coronary arteries of patients soon after the onset of acute myocardial infarction symptoms. ${ }^{5}$ Until that time it had not been appreciated that coronary thrombosis was the underlying pathological process in the majority of cases of myocardial infarction. The natural history of myocardial infarction involves recanalisation of the occluded artery so that intracoronary thrombus was often not seen at necropsy in patients who had died some days after the acute event. Intracoronary streptokinase was found to be effective in re-establishing blood flow in infarct related vessels. ${ }^{6}$ The intravenous agent achieved the same end, haemorrhagic complications being reduced by employing a short duration infusion. ${ }^{7}$

Alternative agents with allegedly greater clot specificity were developed shortly afterwards. These new activators of plasminogen included anisoylated plasminogen-streptokinase activator complex, anistreplase (APSAC), ${ }^{8}$ and recombinant tissue plasminogen activator, rtPA. ${ }^{9}$

\section{Benefits of thrombolysis}

Early treatment with a thrombolytic agent lyses thrombus within coronary arteries and promotes recanalisation. Beneficial effects include limitation of infarct size, improved left ventricular function, and reduced mortality.

Surprisingly, the first report of mortality reduction with intravenous streptokinase comes from as long ago as $1958 .{ }^{4}$ Small studies carried out in the 1960s and 1970s supported these early findings, although concerns over side effects restricted widespread uptake. Several very large, placebo controlled trials reported survival benefits with the three principle thrombolytic agents in the 1980 s. $^{10-13}$ The most extensive description on mortality reduction appeared two years ago when the Fibrinolytic Therapy Trialists (FTT) Collaborative Group published an important review of all nine trials with more than a 1000 patients randomised per trial. Outcome data on almost 60000 patients showed that thrombolysis reduced 35 day mortality after acute myocardial infarction from $11.5 \%$ to $9.6 \%$, saving 20 to 30 lives per thousand treatments, depending on delay to treatment. ${ }^{14}$

Limiting the extent of ischaemic necrosis reduces the risk from left ventricular dysfunction, the principal cause of early and late nonarrhythmic mortality and morbidity. Left ventricular ejection fraction, albeit an inexact measure shortly after acute myocardial infarction, is improved by thrombolysis. ${ }^{15}$ The frequency of dangerous arrhythmia is also reduced, probably by improving the blood supply to the highly arrhythmogenic "penumbra" of critically ischaemic myocardium surrounding the infarcting area.

Improved outcomes depend upon prompt reperfusion of ischaemic myocardium. Suc- 
Table 1 Options for bleeding after thrombolytic therapy

Manual pressure on punctured vessel

Interrupt thrombolytic and anticoagulant therapy

IV fluid replacement or blood

Protamine sulphate, $1 \mathrm{mg}$ per 100 units of heparin given

Cryoprecipitate ( 15 bags) to increase fibrinogen levels to $1 \mathrm{~g} /$ litre

Fresh frozen plasma (2-4 units)

Platelets (4-12 bags)

Epsilon-aminocaproic acid ( $5 \mathrm{~g}$ in $15-30 \mathrm{~min}$ )

Tranexamic acid (1g slow IV injection repeated as necessary)

cessful reperfusion is clinically apparent as an improvement in chest pain accompanied by ECG evidence of at least a $50 \%$ reduction in ST segment elevation. There is also a rapid rise and fall in cardiac enzyme levels in the plasma. Failure to achieve reperfusion may indicate the need to repeat the infusion or refer for urgent angiography.

\section{Adverse effects}

Adverse events are extremely frequent after thrombolytic therapy, particularly when treatment is delayed or given inappropriately. Cardiac arrhythmias, especially self limiting runs of accelerated idioventricular rhythm, may reflect reperfusion. More serious rhythm disturbances such as ventricular tachycardia are more common when a thrombolytic agent has not been given.

\section{HYPOTENSION}

Hypotension accompanies one in 50 treatments. It is mediated by histamine release and vasodilatation, and is sometimes a marker of poor left ventricular function. It may respond to volume replacement but is occasionally severe enough to cause the treatment to be discontinued.

\section{ALLERGY}

Immediate hypersensitivity reactions, more common after streptococcal sore throat, may cause hypotension as well as urticaria and wheezing. However the incidence of acute anaphylaxis was less than $0.1 \%$ in one of the early multicentre studies. ${ }^{10}$ There is no evidence

Table 2 Suggested contraindications to thrombolytic therapy

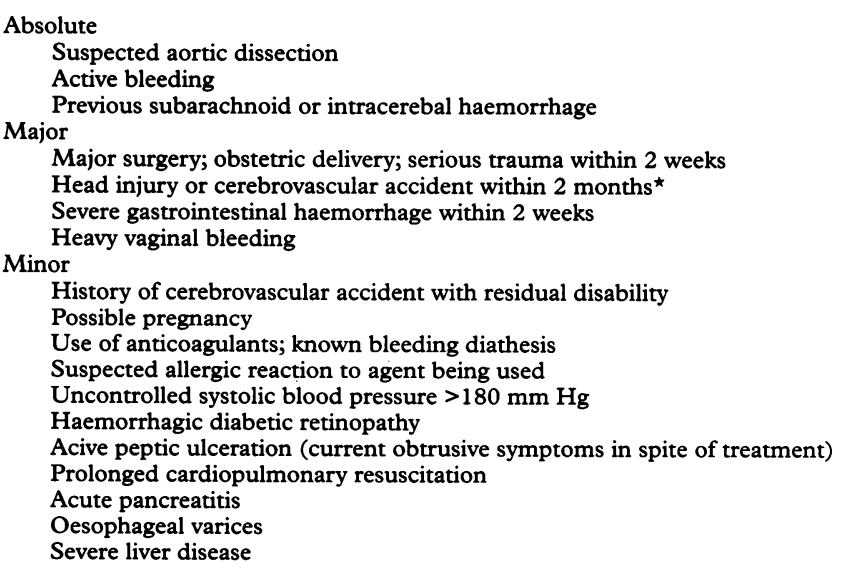

^Even with complete recovery

Reproduced with permission from Vincent R. Myocardial infarction: thrombolysis after infarction. Prescribers Journal 1995;35:140-8. that allergic reactions are prevented by prior administration of corticosteroids or antihistamines.

\section{BLEEDING}

Haemorrhage is a common complication in the first few hours after thrombolytic therapy. Minor episodes, such as ecchymoses or prolonged bleeding from venepuncture sites, occur frequently. Major haemorrhage, defined as intracranial or gastrointestinal bleeding, a $15 \%$ drop in packed cell volume, or haemorrhage requiring transfusion, occurs in $1-2 \%$ despite the exclusion of high risk patients. Treatment options for severe bleeding during or shortly after thrombolysis are listed in table 1 .

STROKE

Cerebrovascular events occur in up to $3 \%$ of cases. Non-haemorrhagic strokes are usually due to embolisation of mural thrombi. Intracranial haemorrhage has a reported incidence of 0.3 to 0.7 per cent. Cerebral bleeding occurs most frequently in the elderly, in hypertensives, and those with a history of previous stroke. Choice of agent is also relevant: in the ISIS 3 study $^{16}$ there were 39 definite cerebral haemorrhages among 12848 patients randomised to receive streptokinase and 92 such events in 12841 patients given rt-PA $(P=0.0001)$.

Outcome data in controlled trials of thrombolytic agents are usually presented as $\mathbf{3 5}$ day survival without disabling stroke. Despite the incidence of three to seven catastrophic strokes per 1000 treatments there is still compelling evidence of absolute benefit when thrombolysis is carried out early in all eligible cases.

The generally accepted contraindications to thrombolytic therapy are listed in table 2 .

\section{Patient selection}

All patients presenting with a history suggestive of acute myocardial infarction are potential candidates for fibrinolytic therapy, but many do not receive the treatment. ${ }^{17} \mathrm{~A}$ major factor in treatment denials may be confusion over eligibility. The large international studies of the 1980 s were inconsistent in terms of exclusion criteria, and up to two thirds of patients were excluded in some trials. For example GISSI ${ }^{10}$ included only patients with definite infarction, while ISIS $2^{11}$ and ASSET ${ }^{13}$ included patients with suspected acute myocardial infarction. The AIMS investigators ${ }^{12}$ employed an upper age limit of 70 years and both AIMS and ISAM $^{18}$ excluded patients with chest pain of more than six hours duration. By contrast there was no upper age limit with GISSI or ISIS 2, and patients were randomised up to 12 and 24 hours respectively after symptom onset. There was also inconsistency between trials with regard to inclusion of patients with cardiogenic shock and those who had had previous acute myocardial infarction.

Contradictory results between studies added to the difficulties of interpretation. In GISSI no benefit was demonstrated with streptokinase after six hours, whereas the ISIS 2 investigators 
showed significant mortality gains up to 12 hours after onset of chest pain. Results from ISIS 2 also showed improved survival with streptokinase in inferior myocardial infarction whereas no such benefit was seen in ISAM or GISSI. Mortality rates in patients with suspected acute myocardial infarction presenting with left bundle branch block (LBBB) were reduced from $28 \%$ to $14 \%$ in ISIS 2 , whereas no significant difference was reported in this subgroup by the GISSI investigators.

The effect of thrombolysis allocation on subgroups distinguished by presenting features was examined in the FTT review of trials. ${ }^{14}$ The odds ratios for death were significantly reduced in patients less than 75 years old presenting within 12 hours of onset of chest pain who had either ST segment elevation or LBBB on the ECG. Other subgroups are considered below.

\section{ELDERLY PATIENTS}

Acute myocardial infarction is twice as common in patients over the age of 75 years and is more often fatal. The mortality of acute myocardial infarction over the age of 75 is five times that of the under 55 years group. There is no evidence to suggest that larger infarctions are responsible for the excess mortality. Necropsy data from the GISSI 2 study revealed a higher incidence of cardiac rupture in fatal cases over the age of 70 compared to those under 60 years of age. ${ }^{19}$ Although the percentage mortality reduction with thrombolysis is less in the older age group, the absolute numbers of lives saved is greater. In the FTT review of trials, this mortality reduction reached statistical significance up to age 74 , with a trend for improved survival in thrombolysis allocated patients over 75 years of age. Another subgroup analysis suggested that one life was saved for 33 thrombolytic treatments in the over 75 years age group, compared with one life saved per 50 treatments in younger patients. $^{20}$ The available evidence does not, therefore, support the adoption of an upper age limit for thrombolysis although in practice older patients often have other contraindications to treatment.

\section{HYPERTENSION}

The data are inconsistent with regard to the utility of thrombolytics in hypertensive patients. The FTT review of trials reported a non-significant trend in favour of treatment, but the confidence limits were wide. The major risk in this group is haemorrhagic stroke and there is some agreement that the agents should be avoided with systolic pressures over $180 \mathrm{~mm}$ $\mathrm{Hg}$. However, transient hypertension will often respond to treatment with opiate analgesia, nitrates, or intravenous $\beta$ blockers where indicated.

\section{HYPOTENSION}

Systolic blood pressures of less than $100 \mathrm{~mm}$ $\mathrm{Hg}$ occur most frequently after anterior acute myocardial infarction. Pooled data presented in the FTT review of trials suggest that thrombolytic therapy is beneficial, reducing mortality from $35.1 \%$ in controls to $28.9 \%$ in the treated group $(P<0.01)$. Control group mortality is higher than average in this subgroup so the absolute number of lives saved is even greater than the percentage reduction suggests. With severe hypotension or cardiogenic shock (clinically apparent as systemic hypotension plus pulmonary oedema) the case for thrombolysis remains to be proved.

PREVIOUS ACUTE MYOCARDIAL INFARCTION

Twenty per cent of patients admitted with acute myocardial infarction will have had a previous infarction and second and subsequent infarctions carry a greater risk of death. The reported mortality reduction from $14.1 \%$ to $12.5 \%$ with fibrinolysis in patients with prior myocardial infarction therefore represents more lives saved per treatment than in patients with first acute myocardial infarction. Streptokinase is contraindicated in the first two years after a previous dose and there is evidence of persistence of neutralising antibodies for at least four years. ${ }^{21} \mathrm{rt}-\mathrm{PA}$ is preferred in these circumstances.

\section{INFERIOR INFARCTION}

In acute inferior wall infarction with ST segment elevation thrombolytic therapy reduced 35 day mortality from $8.4 \%$ to $7.5 \%$ in the FTT review of trials, indicating a trend for improved survival with treatment that did not quite reach statistical significance.

There were different interpretations between the component trials: ISAM failed to show mortality gains with streptokinase after inferior acute myocardial infarction, whereas the ISIS 2 investigators reported significant benefit. Relatively low control group mortality after inferior infarction $(8.4 \% v 16.9 \%$ for anterior acute myocardial infarction) may account for these differences. Inferior wall infarctions tend to be smaller (by number of leads involved) than anterior infarctions. The number of lives saved by fibrinolysis after inferior infarctions is similar to that observed with smaller anterior infarctions.

\section{OTHER ECG FEATURES}

Acute ST elevation is not universal with myocardial infarction. Acute myocardial infarction may present with ST segment depression, for example, or the ECG may be normal. Broadening the criteria to include patients with suspected acute myocardial infarction would enable more rapid thrombolysis in a proportion of patients but the data do not support the use of thrombolytic agents in these circumstances. Subdivision of patients into ECG categories widens the confidence limits, however, and some have argued that no evidence of benefit is not evidence of no benefit. ${ }^{22}$ Others have indicated that, while coronary occlusion mediates acute transmural infarction (presenting with ST elevation), intermittent platelet plugs may be the cause of non- $Q$-wave acute myocardial infarction. The latter are more rationally treated with heparin and aspirin. ${ }^{23}$ This view gains support from the findings of the LATE study in which late 
presenters with non-diagnostic ECGs had a poorer outcome with thrombolysis than without. $^{24}$

Chest pain of non-cardiac origin is more likely in patients without the typical ECG changes of acute myocardial infarction. Pericarditis, peptic ulcer disease, and aortic dissection may all present with cardiac-type pain. In the ASSET study the mortality rate among patients given rt-PA for non-ischaemic chest pain was $9.6 \%$ compared with $1.2 \%$ for placebo. $^{13}$

\section{CARDIOPULMONARY RESUSCITATION}

Prolonged cardiopulmonary resuscitation has been regarded as a contraindication to thrombolytic therapy, but what constitutes prolonged resuscitation has not been specified. Current evidence suggests that there is no significant increase in bleeding complications with thrombolysis even after vigorous cardiopulmonary resuscitation. ${ }^{25-27}$ Major bleeding is more common after prehospital resuscitation, however, and thrombolysis in this situation is relatively contraindicated. ${ }^{28}$

\section{LATE PRESENTERS}

The benefits of thrombolysis are very much time dependent. Very early clot lysis among patients in the TEAHAT $^{29}$ and GREAT $^{30}$ studies prevented the development of full thickness changes in a proportion of patients, indicating a small window of opportunity during which a thrombolytic agent may reverse the process of infarction itself.

In the GISSI study the mortality gain in the first hour after onset of MI symptoms was 47 lives saved per 1000 treatments, reducing to 17 in the third to sixth hours. At more than six hours no significant difference was observed. By contrast, in ISIS 2 benefit was observed up to 24 hours after randomisation but in this study patients were not excluded if the exact time of symptom onset was unknown.

Figure 1 shows the relation between absolute benefit (survival without disabling stroke) and time to treatment in 45000 patients with ST elevation or bundle branch block. ${ }^{14}$ Loss of benefit per hour of delay was 1.6 (SD 0.6) per 1000 patients treated. Benefit was still observed beyond the six hours interval, however. In 22000 patients randomised 7-12 hours after onset of symptoms, mortality was reduced by thrombolysis from $12.7 \%$ to $11.1 \%$ $(\mathrm{P}<0.01)$.

Two other recent studies bear out these findings. The EMERAS study published in $1993^{31}$ examined 35 day mortality in 4534 patients randomised to streptokinase or placebo up to 12 hours after onset of chest pain. Thrombolysis reduced mortality from $14.7 \%$ to $12.7 \%$. In the same year the findings of the LATE study were published, rt-PA was found to reduce 35 day mortality from $11.97 \%$ to $8.9 \% .^{24}$

While it remains true that the maximum gain is achieved by administration of a thrombolytic agent as soon as possible after symptom onset, some infarcts follow a "stuttering" course with myocardial necrosis occurring gradually over a prolonged period of time. Often it may be dif-

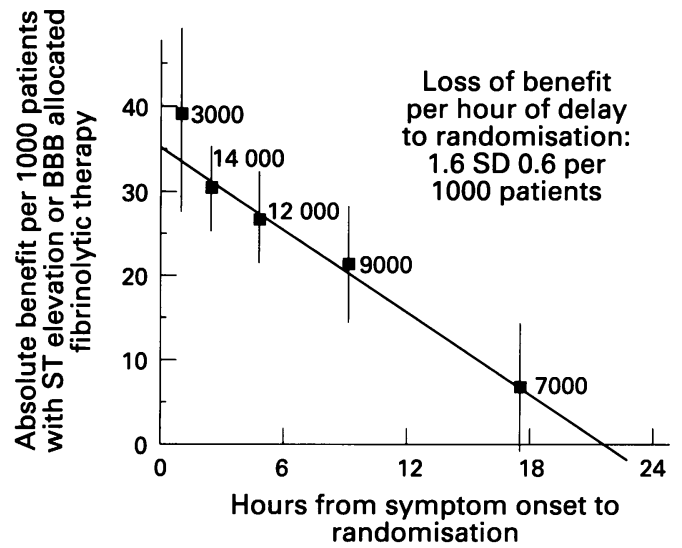

Figure 1 Absolute reduction in 35 day mortality versus delay from symptom onset to randomization among 45000 patients with ST elevation or bundle branch block.

Reproduced with permission from Lancet

(1994;346:311-22; see reference 14).

ficult to determine the exact time of onset of continuous pain in patients presenting with this type of history. Furthermore, even after the process of infarction has begun there may still be some advantage to treating with a thrombolytic agent. Infarct limitation and ventricular salvage are not relevant at this stage-benefits are related to secondary events. Scar formation and remodelling of infarcted areas is more complete in thrombolytic treated patients, leading to fewer dysrrhythmias and less risk from cardiac failure and ventricular aneurysm formation.

Provided there are no other contraindications, therefore, fibrinolysis may be attempted up to 12 hours after the onset of chest pain, even later in cases with a good history and diagnostic ECG.

\section{Choice of agent}

In UK practice streptokinase is the principal drug for in-hospital thrombolysis. It is given as a solution of $1.5 \mathrm{MU}$ in $100 \mathrm{ml}$ of normal saline over one hour. The drug costs approximately $£ 85$ per dose (recommended NHS price). Concomitant therapy is with oral aspirin $300 \mathrm{mg}$ daily indefinitely and subcutaneous heparin 5000 units three times daily or 12500 units twice daily until the patient is ambulant. For prehospital use anistreplase (APSAC) is preferred. This agent is similar to streptokinase but has been chemically modified to permit bolus administration: complexing streptokinase with acylated human lysoplasminogen allows a more rapid onset and prolonged half life. APSAC begins clot lysis within minutes and the effect lasts for four to six hours. It is much more expensive than streptokinase, at $£ 495$ per dose. The dosage regime is 30 units reconstituted in $10 \mathrm{ml}$ of diluent given by slow intravenous injection over five minutes.

Recombinant tissue plasminogen activator (rt-PA), the costliest alternative at $£ 750$, is the agent of choice where there is known allergy to or previous use of streptokinase. rt-PA is a naturally occurring serine protease protein and is manufactured by recombinant DNA techniques. It is more clot specific than streptoki- 
nase and binds to fresh intravascular thrombus. It was previously given over three hours $(10 \mathrm{mg}$ bolus followed by $50 \mathrm{mg}$ over one hour then 40 mg over two hours). More recently an accelerated or "front loaded" schedule has been employed: a $15 \mathrm{mg}$ bolus dose followed by a maximum $50 \mathrm{mg}(0.75 \mathrm{mg} / \mathrm{kg})$ over 30 minutes, then a maximum $35 \mathrm{mg}(0.5 \mathrm{mg} / \mathrm{kg})$ over one hour. Concomitant treatment includes oral aspirin and intravenous heparin in a 5000 unit bolus then 1000 units/h for a minimum 48 hours, aiming for an APTT of 60-85 seconds.

Several important comparative studies were reported in the late 1980s, including GISSI 2 which compared streptokinase and rt-PA with and without heparin ${ }^{32}$ and ISIS 3 , in which all three agents were compared. ${ }^{16}$ At the time rt-PA was the most popular fibrinolytic in North America, mainly because of the TIMI 1 . study of 1986 which showed far superior patency rates for infarct related arteries with rt-PA: $62 \%$ were patent on the 90 minute angiogram versus $31 \%$ for streptokinase. ${ }^{33}$ However, this study had been terminated early and European cardiologists challenged its conclusions on the basis that early recanalisation, which may be transient, is an inadequate outcome measure.

This transatlantic "Battle of the Clotbusters" 34 seemed to have been settled when ISIS 3 reported in 1992. Among more than 41000 patients randomised between streptokinase, APSAC, and rt-PA in 914 hospitals, there was no significant difference in 35-day mortality. The findings are summarised in fig 2. Further evidence in favour of the continued use of streptokinase as agent of choice came from GISSI 2, which also failed to demonstrate survival benefit with rt-PA in its study of 20891 patients. Mortality from acute myocardial infarction in these international megatrials was approximately $10 \%$ regardless of choice of thrombolytic agent. There was a much higher rate of cerebral haemorrhage with rt-PA in the ISIS 3 study $(0.7 \%$ v $0.3 \%, P=0.0001)$ though the difference was not significant in GISSI $2(0.4 \% v 0.3 \%)$.

Despite these data, many North American cardiologists continued to favour rt-PA, citing methodological problems with the megatrials, including outcome differences between European hospitals and their US counterparts, the choice of two different brands of rt-PA, and the delayed subcutaneous heparin regime. Proponents of rt-PA regained some ground with the publication of the GUSTO (global utilisation of streptokinase and TPA for occluded coronary arteries) study. This international study involving 41021 patients randomised to four treatment groups reported lower mortality in the group receiving accelerated treatment with rt-PA and intravenous heparin than in the other three groups: streptokinase plus intravenous heparin, streptokinase plus subcutaneous heparin, and rt-PA plus streptokinase. ${ }^{35}$ Despite an increased rate of haemorrhagic stroke $(0.72 \%$ $v 0.54 \%$ ) there was absolute benefit with rt-PA amounting to nine additional survivors without disabling stroke per 1000 patients treated. The

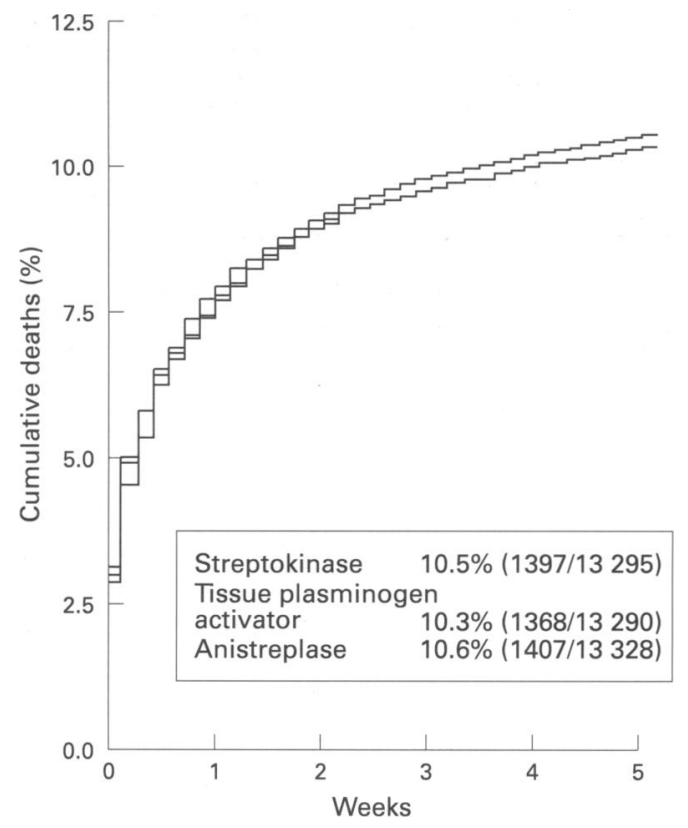

Figure 2 Mortality of three agents compared in ISIS-3. Reproduce with permission from BMF, 1991;302:1259-61 (see reference 34).

greatest survival benefit was observed in the predetermined subsets who presented within four hours of chest pain onset, who were aged less than 75 years, and who had sustained anterior infarction. The mechanism of benefit was shown to relate to increased rates of early recanalisation. In an angiographic subgroup of 2431 GUSTO patients, there was a higher rate of 90 minute patency in the rt-PA treated patients, although interestingly this was not sustained at 180 minutes. ${ }^{36}$

In common with all the major studies, GUSTO has been criticised on methodological grounds. Although it was a prospective randomised controlled trial, GUSTO employed an open label study design. Also, in the data analysis, the streptokinase plus subcutaneous heparin arm was combined with the streptokinase plus intravenous heparin arm. Inconsistencies between study groups have also been noted, including the fact that there was more intervention in the rt-PA group and that excess survivors with rt-PA were only reported in US treated patients. ${ }^{37}$ In light of the high cost of rt-PA, the additional stroke risk and the lack of demonstrable benefit from the agent in the systemic review of major trials, including GUSTO, rt-PA has not become the agent of choice in the United Kingdom. Instead many regional cardiology advisory groups offer guidelines for its use which are similar to those in table 3.

Outside of these limited indications for rt-PA, streptokinase remains the thrombolytic agent of first choice.

\section{Systems for timely thrombolysis}

Several elements contribute to treatment delays, such as the time taken for the patient to seek medical help, the response time of the emergency services, and transfer time to hospital. Once in hospital the "door to needle time", 
Table 3 Indications for tissue plasminogen activator (TPA)

Patients who fulfil ALL the following criteria:-

Presentation equal to or less than 4 hours from onset

Age equal to or less than 75 years

Anterior infarction

Significant persistent hypotension (less than $100 \mathrm{~mm} \mathrm{Hg}$ systolic on several consecutive readings)

Previous myocardial infarction treated with strepokinase or anistrepase (APSAC) AT ANY TIME in the past

Known allergy to strepokinase

Recent proven streptococcal infection also known as the "door to drug interval", should be minimised by a robust triage system which rapidly takes the patient with suspected acute myocardial infarction to the clinical area where thrombolysis may be initiated. Several methods of reducing delays have been evaluated in recent studies.

\section{PREHOSPITAL THROMBOLYSIS}

APSAC and rt-PA are suitable for use in the prehospital arena. EMIP, a large European multicentre study involving 5469 patients, reported a median reduction in pain to needle times of 55 minutes when APSAC was given before transfer to hospital by doctors in mobile coronary care units. ${ }^{38}$ The trial was terminated early when it was found that significant reductions in deaths from cardiac causes were observed, 18 lives being saved per 1000 treatments. The North American MITI study including 360 patients randomised to receive rt-PA from paramedics or after transfer to hospital reported a median reduction of 33 minutes in the prehospital group. This translated into a reduction in hospital mortality from $8.1 \%$ to $5.7 \%$, equivalent to 24 lives saved per 1000 treatments. $^{39}$

In the United Kingdom there has not been overwhelming enthusiasm for prehospital thrombolysis. Some cardiologists have highlighted the delays in the field recording of the cardiograph, lack of physician control, and the problem of ECG interpretation by prehospital personnel. One of the major problems with paramedic administration of these drugs is the need for strict protocols which exclude large numbers of patients. In a preliminary paper by the MITI investigators, Seattle paramedics had to screen 2472 patients to find 107 who satisfied the inclusion criteria for prehospital treatment. ${ }^{40}$ Paramedic skill levels in the administration of thrombolysis tend to decline because of the relatively few occasions where it is appropriate to initiate the treatment in the field. Some studies have failed to show improved survival, and even the two trials cited above did not find a reduction in all cause mortality. Consequently, in the urban setting, patients should be transferred to hospital before thrombolysis, although prehospital identification of elligible patients may reduce delays to treatment. Self referral and admission by emergency ambulance to the nearest accident and emergency department saves time when compared with calling a general practitioner. $^{41}$

In rural communities, where there may be problems of access to hospital, there is a case for domiciliary fibrinolytic therapy. In the
GREAT study of 311 patients living 16 to 62 miles from the nearest district general hospital, domicilliary use of APSAC by general practitioners led to a median time saving of $139 \mathrm{~min}$ utes and a reduction in death rate from $11.5 \%$ to $6.7 \%$, a mortality gain of 48 lives per thousand patients treated. ${ }^{30}$ There were no problems with ECG interpretation among participating general practitioners. At follow up, one year after the conclusion of the study, the mortality rate among those patients treated early after symptom onset was less than half that of the late treated patients, at $10.4 \% v$ $21.6 \% .^{42}$

A\&E DEPARTMENT OR CCU?

A 1994 British Heart Foundation working party report recommended a standard for "call to needle time"-the interval between the patient's first contact with the emergency services and the administration of the drug - of not more than 90 minutes. ${ }^{43}$ The interval most amenable to reduction by hospital practitioners is the "door to needle" time. One North American standard recommends that this interval should not exceed 30 minutes. $^{44}$ Systems aiming to minimise in-hospital delays, described as "fast tracking", are designed to eliminate multiple assessments by junior doctors before admission to the CCU. The diagnosis of acute myocardial infarction is made solely on the basis of the history and the presenting ECG, repeated if necessary. Old ECGs need not necessarily be obtained if not immediately to hand and delays for cardiac enzyme levels or chest radiographs are avoided. This kind of system may lead to time savings of the order of 45 minutes. ${ }^{45}$

More than one model exists for the timely initiation of thrombolysis in hospital. Where rapid admission to a cardiac care unit is not possible the working party recommends that thrombolytic treatment be started in A\&E. In practice this is often the most efficient method. Many studies have reported time savings with $\mathrm{A} \& \mathrm{E}$ initiated treatment. In one trial involving 1934 patients presenting to six hospitals, emergency department thrombolysis was associated with a reduction in door to needle times from a median 80 minutes to 31 minutes. ${ }^{46}$ Supplies of streptokinase and rt-PA may be stored in the $A \& E$ department by arrangement with the hospital pharmacy. A\&E budget holders should anticipate a significant impact on drugs expenditure when rt-PA is widely prescribed within the emergency department (Graham CS, personal communication).

The working party report did not specify which specialty (A\&E or medicine/cardiology) should be responsible for initiating treatment. Ideally this is a decision for relatively senior resident physicians, but $A \& E$ staff are more likely to be immediately available. Provided that agreement can be reached between local cardiologists and $A \& E$ consultants there is no reason why the latter may not take responsibility for the use of thrombolytics in the emergency department. Tight protocols, including a list of contraindications, posted in the 
A\&E department should ensure that the drugs are given appropriately. One small study reported no significant increase in adverse events when thrombolysis was initiated in $\mathrm{A} \& \mathrm{E}$ by A\&E doctors. ${ }^{47}$ Regular clinical audit permits examination of treatment delays and denials, inappropriate prescriptions, and complications of treatment.

\section{Summary and conclusions}

Appropriate use of a thrombolytic agent may save 20 to 30 lives per 1000 treatments.

Thrombolysis should be considered in all patients presenting with cardiac chest pain lasting more than 30 minutes for up to 12 hours after symptom onset. ECG criteria include ST elevation of at least $1 \mathrm{~mm}$ in limb leads and/or at least $2 \mathrm{~mm}$ in two or more adjacent chest leads or left bundle branch block. There is no upper age limit. All patients should also receive oral aspirin and subcutaneous (intravenous with rt-PA) heparin. Other adjuvant treatments have been reviewed previously in this journal. ${ }^{48}$

Streptokinase is the drug of choice except where there is persistent hypotension, previous streptokinase or APSAC at any time, known allergy to streptokinase, or a recent proven streptococcal infection. In these circumstances the patient should receive rt-PA. Additional indications for rt-PA, based on subset analysis by the GUSTO investigators, include patients with ALL of the following: age less than 75 years, presentation within four hours of symptom onset, and ECG evidence of anterior acute myocardial infarction.

Treatment should be initiated as soon as possible. The greatest benefit is observed in patients treated early, pain to treat intervals of less than one hour make possible mortality reductions of nearly $50 \%$. "When" matters more than "where": fast tracking to the CCU is one option but $A \& E$ initiated thrombolysis is feasible and timely. Prehospital thrombolysis is appropriate in certain geographical situations.

The development of practical guidelines for thrombolysis represents the most comprehensive example of evidence based medicine. Streptokinase was first shown to influence outcome in acute myocardial infarction nearly 40 years ago. More recently alternative regimes have been evaluated in several prospective randomised controlled trials yielding pooled data on nearly 60000 patients. However, systematic review of cumulative data reveals a statistically significantmortality gain for intravenous streptokinase over placebo which could have been identified as early as 1971 -at least 15 years before it became generally used in clinical practice. ${ }^{49}$

1 Tillett WS, Garner RL. The fibrinolytic activity of hemolytic streptococci. J Exp Med 1933;58:485-502.

2 Christensen LR, Macleod CM. A proteolytic enzyme of serum:characterization, activation and reaction with inhibitors. J Gen Physiol 1945;28:559-83.

3 Sherry S. The origin of thrombolytic therapy. J Am Coll Cardiol 1989;14:1085-92.

4 Fletcher AP, Alkjaersig N, Smyrniotis FE, Sherry $S$ Treatment of patients suffering from early myocardia infarction with massive and prolonged streptokinase therapy. Trans Assoc Am Physicians 1958;71:287-96.

5 DeWood MA, Spores J, Notske R, Mouser LT, Burroughs $R$, Golden MS, et al. Prevalence of total coronary occlusion during the early hours of transmural myocardial infarction. N Engl J Med 1980;303:897-902

6 Rentrop P, Blanke H, Kostering K, Karsch KR. Acute myocardial infarction: intracoronary application of nitroglycerin and streptokinase in combination with translumina recanalization. Clin Cardiol 1979;2:354-63.

7 Schroder R, Biamino G, Von Leitner ER, Linderer T, Brüggemann $T$, Heitz J, et al. Intravenous short-term infusion of streptokinase in acute myocardial infarction. Circulation 1983;63:536-48.

8 Smith RAG, Dupe RJ, English PD, Green J. Fibrinolysis with acyl enzymes: a new approach to thrombolytic with acyl enzymes: a new appro

9 Ryken DC, Collen D. Purification and characterization of Ryken DC, Collen D. Purification and characterization of
the plasminogen activator secreted by human melanoma the plasminogen activator secreted by human melanom

10 GISSI (Gruppo Italiano per lo Studio della Sopravvivenza nell Infarto Miocardico). Effectiveness of intravenous thrombolytic treatment in acute myocardial infarction. Lancet 1986;i:397-401

11 ISIS-2 (second international study of infarct survival) Collaberative Group. Randomized trial of intravenous streptokinase, oral aspirin, both or neither among 17,187 cases of suspected acute myocardial infarction. Lance 1988;ii:349-60.

12 AIMS (APSAC intervention mortality study) Trial Study Group. Effects of intravenous APSAC on mortality after acute myocardial infarction: preliminary report of a placebo-controlled clinical trial. Lancet $1988 ; \mathrm{i}: 545-9$.

13 R Wilcox RG, Von Der Lippe G, Olsson CG, Jensen G, Skene AM, Hampton JR for the ASSET (AngloScandinavian study of early thrombolysis) study group. Scandinavian study of early thrombolysis) study group. Trial of tissue plasminogen activator for mortality reduc-
tion in acute myocardial infarction. Lancet 1988;ii:525-30. tion in acute myocardial infarction. Lancet 1988;ii:525-30.
4 Fibrinolytic Therapy Trialists' (FTT) Collaborative Group. Fibrinolytic Therapy Trialists' (FTT) Collaborative Group
Indications for fibrinolytic therapy in suspected acute myocardial infarction: collaborative overview of early mortality and major morbidity results from all randomised trials of more than 1000 patients. Lancet 1994;343:311-22.

15 Braunwald E. Myocardial reperfusion, limitation of infarct size, reduction of left ventricular dysfunction and improved survival:should the paradigm be expanded? Circulation 1989;79:441.

16 ISIS-3 (Third International Study of Infarct Survival) Collaberative Group. A randomized trial of streptokinase vs anistreplase and of aspirin plus heparin vs aspirin alone among 41,299 cases of suspected acute myocardial infarcamong 41,299 cases of suspected

17 Muller DWM, Topol EJ. Selection of patients with acute myocardial infarction for thrombolytic therapy. Ann Intern Med 1990;113:949-60.

18 ISAM (Intravenous Streptokinase in Acute Myocardial Infarction) Study Group. A prospective trial of intravenous streptokinase in acute myocardial infarction: mortality, morbidity and infarct size at 21 days. N Engl J Med 1986 314:1465-71.

19 Maggioni AP, Maseri A, Fresco C, Franzosi MG, Mauri F Santoro E, et al. Age related increase in mortality amon patients with first myocardial infarctions treated with thrombolysis. The investigators of the Gruppo Italiano pe lo Studio della Sopravvivenza nell Infarto miocardico (GISSI 2). N Engl J Med 1993;329:1442-8.

20 Krumholz HM, Pasternak RC, Weinstein MC, Friesinger GC, Ridker PM, Tostenson AN, et al. Cost effectiveness of thrombolytic therapy with streptokinase in elderly patients with suspected acute myocardial infarction. $N$ Engl J Med with suspected $1992 ; 327: 7-13$.

21 Elliott JM, Cross DB, Cederholm-Williams SA, White HD. Neutralizing antibodies to streptokinase four years after
intravenous thrombolytic therapy. Am J Cardiol 1993;71: intraven $640-5$.

22 Rawles J. Deciding who should have thrombolysis (letter). BMJ 1993;307:799- 80

23 Channer KS. Deciding who should have thrombolysi (letter). BMJ 1993;307:1146.

24 LATE (Late Assessment of Thrombolytic Efficacy) Study Group. Late assessment of thrombolytic efficacy with altiplase 6-24 hours after onset of acute myocardial infarction. Lancet 1993;342:759-66.

25 Cross SJ, Lee SH, Rawles JM, Jennings K. Safety of thrombolysis in association with cardiopulmonary resuscitation. BMJ 1991;303:1241.

26 Scholz KH, Tebbe U, Herrmann C, Wojcik J, Lingen R, Chemnitius JM, et al. Frequency of complications of cardiopulmonary resuscitation after thrombolysis during acute myocardial infarction. Am J Cardiol 1992;69:724-8.

27 Weston CFM, Avery P. Thrombolysis following pre-hospital cardiopulmonary resuscitation. Int J Cardiol 1992;37: cardiopulr.

28 Tenaglia AN, Califf RM, Candela RJ, Kereiakes DJ, Berrios E, Young SY, et al. Thrombolytic therapy in patients requiring cardiopulmonary resuscitation. Am J Cardio 1991;68:1015- 9 .

29 Risenfors M, Gustavsson G, Ekstrom L, Hartford M, Herlintz J, Karlson BW, et al. Prehospital thrombolysis in suspected acute myocardial infarction:Results from the TEAHAT study. J Intern Med 1991;734(suppl):3-10.

30 GREAT Group. Feasibility, safety and efficacy of domiciliary thrombolysis by General Practitioners: Grampian Region early anistreplase trial. BMJ 1992;305:548-58.

31 EMERAS (Estudio Multicentrico Estreptoquinasa Republicas de America del Sur) Collaberative Group. Randomized trial of late thrombolysis in patients with suspected acute myocardial infarction. Lancet 1993;342:767-72. 
32 GISSI (Gruppo Italiano per lo Studio della Streptochinasi nell'Infarto miocardico) A factorial randomized trial of alteplase versus streptokinase and heparin versus no heparin among 12,490 patients with acute myocardial infheparin among 12,490 patients

33 Chesbro JH, Knatterud G, Roberts R, Borer J, Cohen LS, Dalen J, et al. Thrombolysis in myocardial infarction (TIMI) trial, phase I: a comparison between intravenous tissue plasminogen activator and intravenous streptokinase. Clinical findings through hospital discharge. Circulation 1987;76:142-54.

34 O'Donnell M. Battle of the clotbusters. BMJ 1991;302 1259-61.

35 Global utilization of streptokinase and tissue plasminogen activator for occluded coronary arteries (GUSTO) Investigators. An international randomized trial comparing four thrombolytic strategies for acute myocardial infarction. $N$ Engl J Med 1993;329:673-82.

36 Global utilisation of streptokinase and tissue plasminogen for occluded coronary arteries (GUSTO) investigators. The for occluded coronary arteries (GUSTO) investigators. The effects of tisssue plasminogen activator, streptokinase or both on coronary artery patency,ventricular function and survival after acute

37 Lee KL, Califf RM, Simes J, Van der Werf F, Topol EJ Holding GUSTO up to the light: global utilisation of streptokinase and tissue plasminogen activator for occluded coronary arteries. Ann Intern Med 1994;120:876-81.

38 Leizorovicz A, Boissel JP, Julian D, Castaigne A, Haugh MC (The European Myocardial Infarction Project Group) Prehospital thrombolytic therapy in patients with suspected acute myocardial infarction. N Engl J Med 1993;329:383-9.

39 Weaver WD, Cerqueira M, Hallstrom AP, Litwin PE, Martin JS, Kudenchuk PJ, et al, for the Myocardial Infarction Triage and Intervention (MITI) Project Group.
Prehospital-initiated versus hospital-initiated thrombolytic therapy. JAMA 1993;270:1211-6.

40 Weaver WD, Eisenberg MS, Martin IS, Litwin PE, Shaeffer SM, Ho MT, et al. Myocardial Infarction Triage and Intervention Project-phase 1: patient characteristics and feasivention Project-phase 1: patient characteristics and feasi-
bility of prehospital initiation of thrombolytic therapy. J Am bility of prehospital initiation of

41 Pell ACH, Miller HC. Delays in admission of patients with acute myocardial infarction to coronary care:Implications for thrombolysis. Health Bull 1990;48:225-31.

42 Rawles J. Halving of mortality at one year by domicilliary thrombolysis in the Grampion Region Early Anistreplase Trial (GREAT). J Am Coll Cardiol 1994;23:1-5.

43 Weston CFM, Penny WJ, Julian DG, on behalf of the British Heart Foundation working Group.Guidelines for the early management of patients with myocardial infarction. BMJ 1994;308:767-71.

44 Eisenberg MS. Reducing the door to drug interval for thrombolytic therapy. Acad Emerg Med 1995;2:579-80.

45 Pell ACH, Miller HC, Robertson CE, Fox KAA. Effect of 'fast track' admission for acute myocardial infarction on delay to thrombolysis. BMJ 1992;304:83-7.

46 Birkhead JS. Time delays in provision of thrombolytic treatment in six district hospitals. Joint Audit Commitee of the British Cardiac Society and a cardiological commitee of the Royal College of Physicians of London. BMJ 1992;305 445-8.

47 Nee PA, Gray AJG, Martin MAM. Audit of thrombolysis initiated in an accident and emergency department. Quality in Health Care 1994;2:29-33

48 Vincent $R$. Advances in the early diagnosis and management of acute myocardial infarction. J Accid Emerg Med 1996;13:74-9.

49 Mulrow CD. Rationale for systematic reviews. In: Chalmers I, Altman DG, eds. Systematic reviews. London: BMJ publishing group, 1995.

\section{THE FACULTY OF ACCIDENT AND EMERGENCY MEDICINE SPECIALTY EXAMINATION}

The Specialty Examination of the Faculty of Accident and Emergency Medicine will be held on the following dates

21/22 May 1997 at the Royal College of Surgeons of Edinburgh Closing date - 26 March 1997 Fee $-£ 550$

12/13 November 1997 at the Royal College of Surgeons of England Closing date - 17 September 1997

Fee $-£ 600$

Regulations and application forms are available from:

The Secretariat

Intercollegiate Specialty Boards

3 Hill Square

Edinburgh

EH8 9DR

Tel: 01316629222

Facs: 01316629444 